\title{
Sprengel deformity associated with winging of scapula, vertebral fusion, rib fusion and spina bifida occulta
}

\author{
Satvik N Pai (D), Mohan M Kumar
}

Department of Orthopaedic Surgery, Sri Ramachandra Institute of Higher Education and Research, Chennai, Tamil Nadu, India

\section{Correspondence to \\ Dr Satvik N Pai;}

satvik.pai@gmail.com

Accepted 2 October 2021
Check for updates

(C) BMJ Publishing Group Limited 2021. No commercial re-use. See rights and permissions. Published by BMJ.

To cite: Pai SN,
Kumar MM. BMJ Case
Rep 2021;14:e246815.
doi:10.1136/bcr-2021-
246815

\section{DESCRIPTION}

An 11-year-old girl was brought to us with complaints of restriction of movements of the left shoulder and a deformity of the back for the past 1 year, which had gradually progressed over 1 year. The child was yet to attain menarche. On examination, her physical development was found to be Tanner stage II. She was found to have rightsided thoracic scoliosis. The left scapula was at a higher level compared with the right and medially rotated. Crowding of ribs was present on the left side. Examination of the left shoulder revealed restricted abduction and flexion. Marked wasting of left supraspinatus, infraspinatus and periscapular muscles was present, with winging of scapula (figure 1).

Radiographs of the spine showed a right-sided thoracic scoliosis (figure 2A). Fusion of D3-D6 vertebra was seen. Fusion of left fourth, fifth and sixth ribs was present. Apex of the thoracic curve was found to be D7 vertebra (figure 2B). C7 plumb line and central sacral vertebral line were found to be almost coinciding (figure 2C), indicating it was a well-compensated scoliosis. Superior and inferior end vertebra were identified to be $\mathrm{D} 2$ and $\mathrm{D} 7$, respectively (figure 2D). Apical vertebral translation was measured to be $10.42 \mathrm{~mm}$. Cobb's angle was measured to be 35 degrees (figure 2E). The Cobb's angle was greater than 25 degrees in side bending radiographs, indicating it to be structural scoliosis (figure 2G, H). The rib vertebral angle difference was found to be 62 degrees (figure 2I, $\mathrm{J}$ ), with rib phase II (figure $2 \mathrm{~K}$ ), indicating the curve is at a high risk for progression. Risser's index was found to be grade $\mathrm{O}$ (figure $2 \mathrm{~F}$ ).

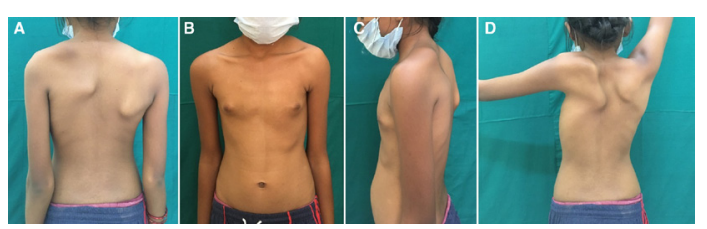

Figure 1 Clinical images showing (A) high riding scapula on the left side; inferior angle of left scapula present more medially compared with the right side. (B) Medial border of scapula seen as a prominence in the left supraclavicular region; presence of breast buds indicating Tanner stage II physical development. (C) Wasting of left side supraspinatus, infraspinatus and periscapular muscles compared with the right side. (D) Limitation of abduction of left shoulder compared with right, with undue prominence of left scapula indicating winging of scapula due to periscapular muscle wasting/hypoplasia.

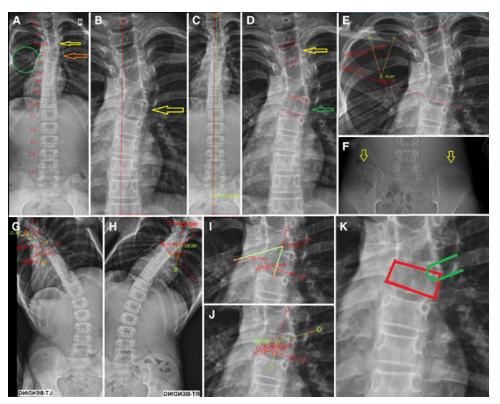

Figure 2 Radiological analysis showing $(\mathrm{A})$ radiograph of spine covering from $\mathrm{C} 7$ to sacrum; right-sided thoracic scoliosis (orange arrow) with fusion of D3-D6 vertebrae (yellow arrow) and fusion of left fourth,fifth and sixth ribs (green circle). (B) C7 plumb line (red) and apical vertebra identified as D7 vertebra (yellow arrow). (C) C7 plumb line (red) and central sacral vertebral line (green) almost coinciding indicating a well-compensated scoliosis. (D) Superior end vertebra identified as D2 (yellow arrow), inferior end vertebra identified as D7 (green arrow). (E) Cobb's angle (green) measured to be 35 degrees. (F) Risser's index found to be grade 0 as the iliac apophysis was not visible on the radiograph (yellow arrows). ( $\mathrm{G}$ and $\mathrm{H}$ ) Side bending radiographs, showing Cobb's angle (green) to be greater than 25 degrees, suggesting the scoliosis is structural. (I and J) Rib vertebral angle (green) on left (57 degrees) and right side (119 degrees), respectively, from which rib vertebral angle difference was calculated to be 62 degrees, indicating high likelihood of progression of scoliotic curve. (K) Rib phase II indicated by the overlap of the rib (green) and vertebral body (red), suggesting a high likelihood of progression of scoliotic curve.

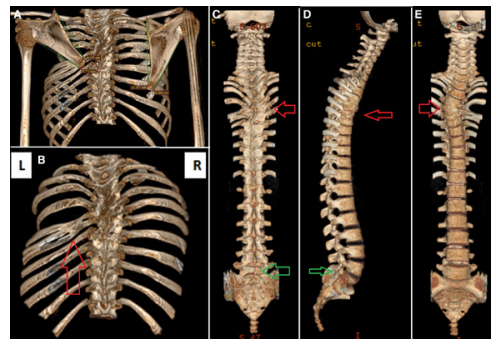

Figure 3 CT reconstruction showing (A) hypoplastic left scapula as indicated by comparison of length of medial and lateral borders of scapula on both sides. (B) Fusion of left fourth, fifth and sixth ribs (red arrow). (C,D and E) Fusion of D3-D6 vertebra (red arrow) and bifid L5 spinous process (green arrow) indicating spina bifida occulta. 
CT scan additionally showed a bifid spinous process of L5, indicating spina bifida occulta (figure $3 \mathrm{C}$ and D). The left scapula had a shorter medial and lateral border compared with the right side and was at a higher level and medially rotated compared with the right side (figure 3A). MRI showed the presence of a fibro-osseous omovertebral bar between the inferior margin of the left scapula and the spinous process of D5. No spinal cord anomalies were noted.

Sprengel deformity is a rare condition caused due to abnormal descent of scapula during embryonic development. It is often

\section{Patient's perspective}

We visited several doctors and were told that our daughter had a problem in her spine. However, the real problem faced by her was due to her being unable to lift her left arm completely. Only after the CT and MRI were done at this hospital were we told that there was a problem in her left shoulder region as well. Only then were we explained the exact nature of the problem and what the further plan of action is going to be. She has learnt to do all activities with the left hand, but the left shoulder looking abnormal is the only real problem she continues to face.

\section{Learning points}

Sprengel deformity should be differentiated from scoliosis by the presence of a high riding scapula.

- Sprengel deformity can be associated with several other conditions like scoliosis, vertebral fusion, omovertebral bar, spina bifida and rib fusion.

- Every individual with sprengel deformity should undergo thorough examination of the spine along with imaging of the entire spine and thorax to identify associated anomalies. misdiagnosed as scoliosis or often missed when associated with scoliosis. ${ }^{1}$ Sprengel deformity may be associated with KlippelFeil syndrome, omovertebra, spina bifida, rib anomalies, ${ }^{2}$ musculoskeletal dysfunctions and tethered cord syndrome. ${ }^{3}$ It may also be associated with cardiac anomalies, renal anomalies, tracheoesophageal fistulas anal atresia, absence of pectoral muscles and hand anomalies. Our case of sprengel deformity with a hypoplastic scapula, winging of scapula, with concomitant fused vertebra, omovertebral bar, spina bifida occulta and rib fusion is an extremely rare combination. This further emphasis the need for complete evaluation of any patient with sprengel shoulder for other anomalies. A thorough examination of all systems is a must. We recommend radiographs, CT and MRI of the entire spine, along with screening of the thorax to identify associated anomalies, planning of management and prognosis.

Contributors SNP obtained the clinical images of the patient and digital images of all investigations of the patient and was responsible for the writing of the draft of the manuscript. MMK was the chief orthopaedic surgeon under whom the patient was evaluated and guided the entire process of preparation of the article, including reviewing the article. SNP and MMK were both involved in the evaluation of the patient, analysis of radiographs and patient care.

Funding The authors have not declared a specific grant for this research from any funding agency in the public, commercial or not-for-profit sectors.

Competing interests None declared.

Patient consent for publication Consent obtained from parent(s)/guardian(s)

Provenance and peer review Not commissioned; externally peer reviewed.

\section{ORCID iD}

Satvik N Pai http://orcid.org/0000-0002-3621-150X

\section{REFERENCES}

1 Harvey EJ, Bernstein M, Desy NM, et al. Sprengel deformity: pathogenesis and management. J Am Acad Orthop Surg 2012;20:177-86.

2 Öner A, Aşansu MA, Akman YE. Sprengel deformity: comprehensive evaluation of concomitant spinal and Extraspinal anomalies in 90 patients. Spine 2020;45:E1150-7.

3 Mittal N, Majumdar R, Chauhan S, et al. Sprengel's deformity: association with musculoskeletal dysfunctions and tethered cord syndrome. BMJ Case Rep 2013;2013:bcr2013009182.

Copyright 2021 BMJ Publishing Group. All rights reserved. For permission to reuse any of this content visit

https://www.bmj.com/company/products-services/rights-and-licensing/permissions/

BMJ Case Report Fellows may re-use this article for personal use and teaching without any further permission.

Become a Fellow of BMJ Case Reports today and you can:

- Submit as many cases as you like

- Enjoy fast sympathetic peer review and rapid publication of accepted articles

- Access all the published articles

- Re-use any of the published material for personal use and teaching without further permission

Customer Service

If you have any further queries about your subscription, please contact our customer services team on +44 (0) 2071111105 or via email at support@bmj.com.

Visit casereports.bmj.com for more articles like this and to become a Fellow 